\title{
Gastrointestinal Involvement in Langerhans Cell Histiocytosis: Computerized Tomography Findings
}

\author{
Nihal OZDEMIR ${ }^{1}$, Ibrahim ADALETLI ${ }^{2}$, Tiraje CELKAN ${ }^{1}$ \\ ${ }^{1}$ Istanbul University, Cerrahpasa Faculty of Medicine , Department of Pediatric Hematology Oncology \\ ${ }^{2}$ Istanbul University, Cerrahpasa Faculty of Medicine, Department of Pediatric Radiology, Istanbul, TURKEY
}

To Editor,

Langerhans cell histiocytosis $(\mathrm{LCH})$ is a rare histiocytic disorder characterized by abnormal proliferation of bone marrow-derived Langerhans cells. It has a wide clinical spectrum ranging from solitary lesions of bone or skin to fatal multiorgan involvement. ${ }^{1}$ Gastrointestinal (GI) tract involvement is very rare in $\mathrm{LCH}^{2,3} \mathrm{~A}$ review of the English literature of articles published between 1996 and 2004 showed only 24 affected patients. ${ }^{3}$ Here we report a child with extensive $\mathrm{LCH}$ involvement of the distal ileum and colon.

A 4 year old boy presented with persistent rash, hepatosplenomegaly and diffuse lymphadenopathy. His birth and postnatal history were unremarkable. At 4 months of age, he was investigated for lymphadenopathy and lymph node biopsy was consistent with reactive hyperplasia. Complete blood count was normal. At 9 months of age, he was operated for bowel invagination. Later he developed a persistent widespread scaly rash which was diagnosed as seborrheic dermatitis. He was referred to our clinic for further invesigation. A skin biopsy showed clusters of cells stained positive for S100 protein and CD1a which suggested a diagnosis of LCH. Skeletal survey was normal. Treatment with weekly vinblastine and daily oral prednisolone was started. After 6 weeks of therapy, the patient was asymptomatic but his rash flared again during steroid weaning. He was started another course of induction therapy and showed same reactivation of rash during weaning period. He further received etoposide, vinblastine, steroids and local tacrolimus therapy based on an individualized protocol for 3 weeks. There was no active disease and maintenance therapy was given (6-mercaptopurine, prednisolone and weekly methotrexate). The patient had a relapse during maintenance with aurial discharge, rash and Coombs positive hemolytic anemia. He then further received 3 cycles of 2-chloro de oxyadenosine-2Cda (Cladribine) every 3 weeks. After the last course of therapy, he still had persistent disease with hepatosplenomegaly and mild rash. One year after the initial diagnosis, he developed fever, aggrevated rash, severe diarrhea, abdominal pain and distension when he was not on immunosuppresive treatment. Investigations revealed anemia, thrombocytopenia and hypoalbuminemia. Liver function tests were normal, there was no protein in the urine. Stool assays for bacteria, virus, parasites and Clostridium difficile toxin were negative. Colonoscopy could not be performed due to septic clinical picture. An abdominopelvic computed tomography (CT) was requested. Intravenous contrast-enhanced $\mathrm{CT}$ showed diffuse marked circumferential wall thickening of the the whole colonic segments and distal ileal segments. Mucosal contrast enhancement, mural stratification, and surrounding fat stranding of intestinal segments were demonstrated (Figure 1a and 1b). There was minimal free intraperitoneal fluid. Pneumatosis intestinalis and free intraperitoneal air were not detected. He was started on antibiotics to cover invasive colitis and was given multiple albumin infusions but despite that his albumin was low. The patient decompensated on followup and died from refractory disease.

Typically, intestinal LCH is part of a wide-spread severe disease and has dismal prognosis. Although GI involvement is not a criteria for poor prognosis, reports show that more than half of the patients die within $1 \frac{1}{2}$ years of diagnosis. ${ }^{4}$ 

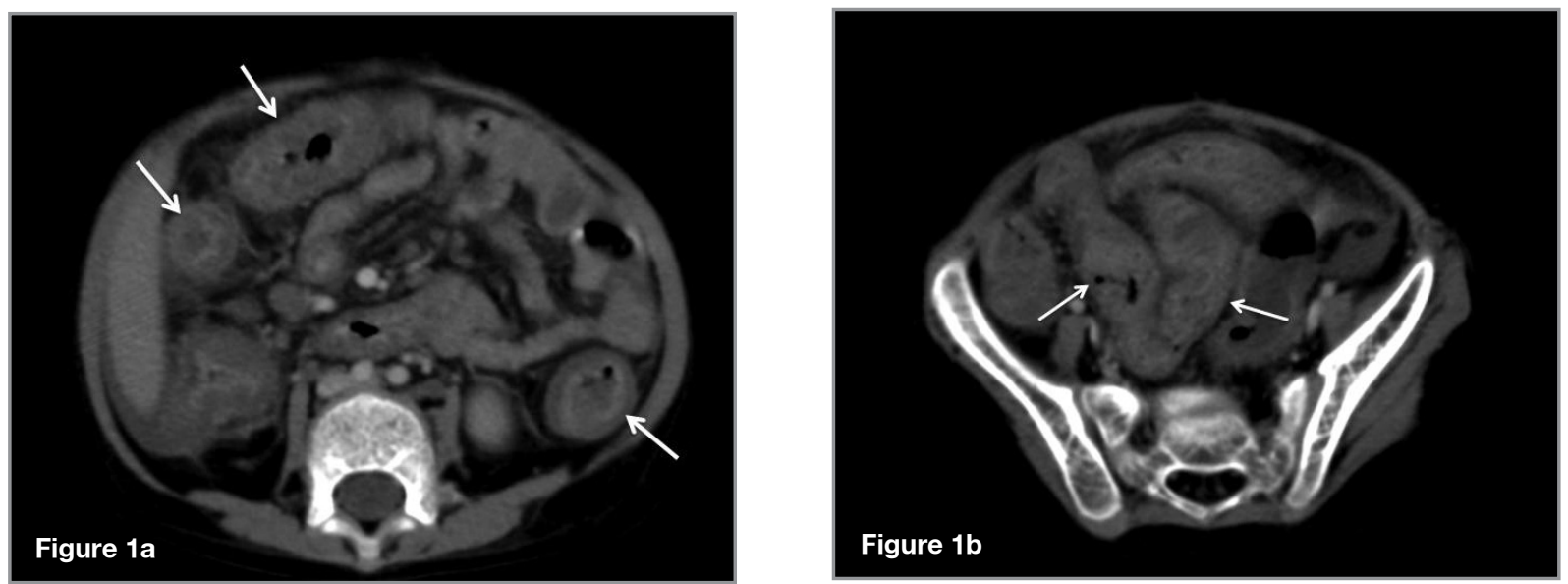

Figure 1. Diffuse wall thickening of the colonic segments and distal ileum of CT

It is more common in children and male compared to adults and female; it peaks under the age of 2 years. ${ }^{4}$ Most common presenting findings are failure to thrive, diarrhea, bloody stool, anemia, hypoalbuminemia and protein losing enteropathy. In $85 \%$ of patients, GI symptoms are preceded by skin rash. ${ }^{3}$ In small bowel, LCH affects most commonly the terminal ileum causing malabsorption and protein losing enteropathy. Disease may be limited to the colon in some patients. Endoscopy and biopsy are the gold standart for diagnosis. However in our patient an abdominal CT was requested because endoscopy could not be performed due to the unsuitable condition of the patient. A major advantage of CT is that it is easily obtained and gives remarkable information about intestinal involvement. Patient's clinical history and specific radiological signs play vital roles in making a differential diagnosis in a patient with bowel wall thickening. Most common causes of bowel wall thickening are hemorrhage, infection, inflammatory bowel disease and edema. ${ }^{5}$ Other less frequent etiologies are lymphomas, hemangioma and LCH. Pseudomembranous colitis may also cause diffuse colonic involvement in immunosuppressive patients.

Standart therapy of LCH is composed of corticosteroids, vinblastine and 6-mercaptopurine. Secondline treatment options are either the combination of vincristine, prednisone and cytarabine or 2-Cda as a single agent. 2-CdA is a purine analogue and has cytotoxic effect on monocytes. There is no specific therapy for GI involvement however GI involved $\mathrm{LCH}$ is adviced to be treated as multisytemic disease irrespective of the patient's clinical condition.

Here we report gastrointestinal involvement of in a child with relapsed LCH. Gastrointestinal involvement should be considered in LCH patients with unexplained diarrhea, failure to thrive or evidence of malabsorption. Computed tomograpy is a helpful diagnostic modality in suspected, selected cases. Gastrointestinal tract involvement has dismal prognosis and should be aggressively treated.

\section{REFERENCES}

1. Yagci B, Varan A, Caglar M, et al. Langerhans cell histiocytosis: retrospective analysis of 217 cases in a single center. Pediatr Hematol Oncol 25: 399-408, 2008.

2. Singhi $A D$, Montgomery EA. Gastrointestinal tract langerhans cell histiocytosis: A clinicopathologic study of 12 patients. Am J Surg Pathol 35: 305-310, 2011.

3. Geissmann F, Thomas C, Emile JF, et al. Digestive tract involvement in Langerhans cell histiocytosis. The French Langerhans Cell Histiocytosis Study Group. J Pediatr 129: 836-845, 1996

4. Hait E, Liang M, Degar B, et al. Gastrointestinal tract involvement in Langerhans cell histiocytosis: Case report and literature review. Pediatrics 118: e1593-1599, 2006.

5. d'Almeida M, Jose J, Oneto J, Restrepo R. Bowel wall thickening in children: CT findings. Radiographics 28: 727 $746,2008$.

\section{Correspondence}

Dr. Nihal ÖZDEMiR

İstanbul Üniversitesi Cerrahpaşa Tıp Fakültesi

Çocuk Hematoloji Onkoloji Bilim Dalı

Cerrahpaşa, ISTANBUL / TURKEY

Tel: (+90.212) 4143000

Fax: (+90.212) 6321282

E-mail: gnozdemir@hotmail.com 